\title{
UMA BREVE HISTÓRIA DO ENSINO DE FILOSOFIA: BRASIL E ALAGOAS EM REVISTA
}

\section{A BRIEF HISTORY OF THE TEACHING OF PHILOSOPHY: BRAZIL AND ALAGOAS IN REVIEW}

Resumo: $O$ presente artigo tem como objetivo revisitar a história do ensino de Filosofia no Brasil e em Alagoas. Como se constitui a trajetória dessa prática em nível nacional e locale Por meio de uma pesquisa bibliográfica em escritos de autores que abordam a história do ensino de Filosofia, bem como de uma pesquisa documental, percebemos as idas e vindas, presenças e ausências desse ensino na educação formal. Cada nova reforma nos currículos ameaça a presença da Filosofia nos currículos escolares, urge, então, defender a sua permanência, apontando a sua especificidade diante das outras disciplinas, isto é, mostrando aquilo que justifica sua presença nas escolas.

Palavras-chave: Alagoas; Brasil; Ensino de Filosofia; História da Educação.

Resumen/Abstract: This article aims to revisit the history of Philosophy teaching in Brazil and in Alagoas. How is the trajectory of this practice constituted at the national and local levels? Through a bibliographical research in writings of authors that approach the history of the teaching of Philosophy, as well as of a documentary research, we perceive the comings and goings, presences and absences of this teaching in formal education. Each new reform in the curricula threatens the presence of Philosophy in school curricula, and it is urgent to defend its permanence, pointing out its specificity in relation to other disciplines, that is, showing what justifies its presence in schools.

Keywords: Alagoas; Brazil; History of Education; Teaching Philosophy. 


\section{INTRODUÇÃO}

A história do ensino de Filosofia em Alagoas, assim como no nível nacional, é marcada por presenças e ausências desse ensino no âmbito da educação formal. Em solo alagoano, apenas no fim do que chamamos de período colonial, é que o ensino de Filosofia aparece, conforme registrado na literatura existente sobre o período. Entretanto, a prática deste ensino já se dava há muito tempo com a presença dos padres jesuítas em terras brasileiras.

O primeiro passo para o ensino de Filosofia no Brasil se deu com a chegada dos primeiros missionários jesuítas, os quais aqui aportaram no ano de 1549. Com o objetivo precípuo de converter e docilizar as almas dos infiéis - os índios - teve início, nessas terras, um sistemático trabalho educacional. A fundação de diversos colégios em toda a colônia fortalece a ideia da instrumentalização da educação para fins religiosos.

O que apresentamos aqui é a reconstrução histórica da trajetória do ensino de Filosofia em Alagoas, contextualizada com o que acontecia em cenário nacional com esse ensino. Como veremos adiante, a questão de saber se existe ou não uma Alagoas colonial (CAETANO, 2010) não é o foco de nossa pesquisa, porém, partindo das datas e divisão didática já consolidadas, não podemos falar de um ensino de Filosofia em terras Alagoanas antes de 1817, uma vez que não havia uma "Alagoas" antes desse período.

A constituição do que hoje chamamos Alagoas começou com a fundação do povoado de São Francisco, em 1570; a ocupação de Nossa Senhora da Apresentação de Porto Calvo, em 1575; e a criação do povoado de Santa Maria Madalena da Alagoa do Sul, em 1614 - os quais foram elevados à vila no mesmo ano de 1636 (CAETANO, 2010). Contudo, foi somente em 1706, no dia 06 de outubro, que foi criada a Comarca das Alagoas, formada por essas três localidades, a qual passou a ser comarca de fato somente em 1712 (CAETANO, 2010). E, finalmente, em 1817, no dia 16 de outubro, Alagoas se tornou território emancipado de Pernambuco, permitindo, então, falar de uma educação Alagoana.

A reconstrução histórica que empreendemos, apesar do contexto apresentado anteriormente, trará uma breve narrativa sobre o ensino de Filosofia na colônia. Que Filosofia é essa? Aqui se põe uma questão: podemos falar, no percurso dessa prática em terras brasileiras - e alagoanas - de Filosofia ou filosofias? Uma questão bem colocada por Domingues (2017), em sua obra "Filosofia no Brasil: legados e perspectivas - ensaios metafísicos", da qual buscamos obter contribuições para o trabalho que ora apresentamos.

A pesquisa tem seu desenvolvimento apresentando os passos do ensino de Filosofia no período do Brasil Império, em âmbito nacional e local - Alagoas - bem como do período republicano, desde sua proclamação até os dias mais próximos de nós. Nas narrativas apresentadas fazemos uma exposição dos períodos mencionados, ora trazendo à tona o cenário local, ora o cenário nacional, e ainda, a percepção de que Filosofia foi presente em cada momento de nossa história.

O nosso objetivo com esse trabalho é contribuir com as investigações sobre a história da educação brasileira e alagoana, bem como sobre o ensino de Filosofia, na ampliação de literatura existente sobre a temática, com a clareza de que não há um esgotamento da questão e que novas e outras narrativas podem confluir com nosso objetivo. A metodologia utilizada foi a pesquisa bibliográfica, a partir da leitura de diversos estudiosos e historiadores da educação.

O artigo se divide em quatro tópicos: Primeiros passos (1817 - 1822); Uma tentativa de sistematização (1823 - 1888); As reformas e o ensino de Filosofia (1889 - 1929); Presenças e ausências do ensino de Filosofia (1930 - 2017). No primeiro tópico, discorremos sobre os primeiros passos do ensino de Filosofia no Brasil, com a chegada e a ação dos padres jesuítas; no tópico seguinte, apresentamos o contexto inicial do ensino de Filosofia em Alagoas e a tentativa de se oferecer uma organicidade ao ensino como um todo; no terceiro tópico, explanamos a situação do ensino de Filosofia no contexto das diversas reformas educacionais do período; e por fim, no último 
tópico, apresentamos um período da história da educação marcado por presenças e ausências do ensino de Filosofia nos currículos da educação formal.

\section{PRIMEIROS PASSOS (1817 - 1822).}

O território que hoje denominamos de Alagoas pertencia à antiga capitania de Pernambuco. É só em 1817, que esse território alcança sua emancipação política. Até aí não podemos falar do ensino de Filosofia nessas terras. Em nível de colônia, podemos destacar, nesse período, três acontecimentos importantes para a Filosofia no Brasil: a chegada dos missionários da Companhia de Jesus, a fundação dos colégios realizada por eles e sua expulsão do território brasileiro.

O ano de 1549 marcou a chegada dos primeiros missionários jesuítas ao Brasil. Durante sua permanência nessas terras, os missionários se dedicaram a um sistemático trabalho educacional, o qual possuía um caráter profundamente religioso, objetivando a docilização e conversão das almas dos infiéis, de modo prioritário, dos habitantes primitivos da "nova" terra.

A partir de 1556, para intensificar a ação educacional e evangelizadora, os missionários iniciaram a fundação de colégios em toda a colônia. Podemos destacar cinco ou seis colégios nos quais existiu o curso de Filosofia, estando estes nas localidades que hoje conhecemos por Rio de Janeiro, São Paulo, Olinda, Recife, Maranhão e Pará (MORAES FILHO, 1959).

O regime desses centros de ensino era definido pelo documento conhecido como Ratio Studiorum, o qual determinava a organização dos estudos em cinco anos para Letras e sete para os estudos de Filosofia e Teologia. Já em 1586, o ensino era organizado em torno de três cursos: de Artes (filosofia e ciências), com duração de três anos, com o primeiro ano dedicado a Aristóteles e Tomás de Aquino; de Teologia; e de Ciências Sagradas (MORAES FILHO, 1959).

A Filosofia ensinada, como podemos notar pelos pensadores estudados, possuía um viés religiosos, eclesiástico. Segundo Domingues (2017), a Filosofia do período colonial era para as elites, uma vez que $95 \%$ da população era analfabeta, com grande déficit linguístico e cultural. Uma Filosofia erudita, ensinada de forma enciclopédica, não muito preocupada com o livre-pensar.

A expulsão dos jesuítas, em 1759, trouxe sérias consequências para o ensino de Filosofia e para a educação formal, de maneira geral. visto que a relativa sistematização e organicidade do ensino foram destruídas, substituídas por um formato de aulas avulsas, chamadas de aulas régias, de caráter estritamente propedêutico para o ensino superior, mas sem conexão entre os níveis de ensino.

A partir de 1817, podemos falar de uma Alagoas, e posteriormente, de um ensino de Filosofia em Alagoas, em 1820, o qual acontecia no formato das aulas régias, na capital da província - à época, Santa Maria Madalena da Alagoa do Sul, hoje Marechal Deodoro, onde também existia uma cadeira de Geometria (VERÇOSA, 2006).

O ensino de Filosofia estava presente desde o embrião de nossa educação formal, ainda que com características diversas da Filosofia de nossos dias, mais como serva do que como senhora, uma filosofia submissa à teologia, caracterizada pela repetição de ideias, além de possuir um caráter meramente descritivo (BROCANELLI, 2010). Mesmo com a saída dos jesuítas, seu ensino permaneceu ocorrendo em terras brasileiras. Seriam necessários mais alguns anos para que sua presença na educação formal fosse questionada.

\section{UMA TENTATIVA DE SISTEMATIZAÇÃO (1823 - 1888)}

A expulsão dos jesuítas levou a total desorganização do ensino brasileiro. Adotou-se um método de aulas avulsas, o qual permaneceu durante um bom tempo, mesmo após a proclamação 
da independência, em 1822. No campo da educação, de modo geral, podemos destacar a primeira lei sobre a instrução pública, de 1827, a qual mandava "criar escolas de primeiras letras em todas as cidades, vilas e lugares mais populosos do Império" (BRASIL, 1827, p. n). O que, na prática, não se realizou, uma vez que os esforços dos governantes estavam concentrados no ensino secundário e superior, os quais visavam a formação da elite dirigente do país.

O Ato Adicional de 1834 foi de grande importância para a ensino secundário, uma vez que conferia às províncias o direito de legislar sobre a instrução pública. Foi a partir daí que as províncias deram início à criação dos Liceus Provinciais, dos quais o mais importante foi o Colégio Pedro II, criado em 1837, na cidade do Rio de Janeiro e mantido pelo poder central. Nesse estabelecimento o ensino de Filosofia obteve relevância, servindo o currículo desse colégio como referencial para os estabelecimentos congêneres em todo o país, em época posterior.

O direito dado às províncias fez com que em Alagoas, após a instalação da Assembleia Legislativa da Província, em 1835, se criassem duas cadeiras para a Vila de Penedo, a saber: uma de Filosofia e uma de Francês. Neste mesmo ano existiam em Maceió dez cadeiras do ensino secundário, as quais eram cinco de Latim, duas de Francês, uma de Retórica, uma de Filosofia, e uma de Aritmética, para 120 alunos provenientes das classes mais abastadas.

A criação do Liceu Provincial de Alagoas ocorreu em 1849, por meio da Lei n. 106, de 05 de maio.

Crear-se-há nesta capital um lyceu composto das cadeiras seguintes: - grammatica nacional e analyse dos classicos portugueses, - grammatica latina, - grammatica franceza, - grammatica inglesa, arithmetica, algebra e geometria, - geografia, chronologia e historia, rhetorica e poetica, - philosophia racional e moral (ALAGOAS, Lei provincial n. 106, de 5 de maio de 1849 apud SANTOS, 2017, p. 03).

A lei de criação do Liceu de Alagoas deixa explícita a presença da cadeira de Filosofia em seu "currículo". O primeiro a ocupar essa cadeira foi Inácio Hipólito Gracindo. Para ela era destinada uma hora e meia de exercícios por dia (SANTOS, 2017). É interessante notar como os fatos na província alagoana seguiram aquilo que acontecia em demais lugares do território brasileiro, como exposto anteriormente.

A presença da Filosofia no Liceu de Alagoas não perdurou por muito tempo. Em 1861, por meio da lei n. 370, de 04 de julho, o estabelecimento de ensino foi extinto pelas seguintes razões: indisciplina dos alunos e a considerada ineficiência do ensino ali ministrado. Restaram ainda três cadeiras em Maceió, das quais a Filosofia não era uma delas, pois não houve frequência para a cadeira, apesar de cinco matrículas efetuadas.

O Liceu foi restabelecido em 1863, com seis cadeiras, dentre as quais a Filosofia não se fez presente. Contudo, a presença do ensino de Filosofia em Alagoas foi registrada na cidade de Penedo, em 1870, onde se ensinava, além da Filosofia, a Retórica, visto que eram exigências para o curso de Direito (COSTA, 1931), um dos cursos mais disputados entre os mais dotados de recursos econômicos.

O cenário nacional, alguns anos depois, em 1879, foi palco da reforma educacional de Leôncio de Carvalho, a qual estabeleceu normas e reformas para o ensino secundário e superior em todo o país. No currículo do ensino secundário não houve menção alguma ao ensino de Filosofia, com a exceção do Colégio Pedro II, no qual a cátedra de Filosofia permaneceu (MORAES FILHO, 1959) e, das Escolas Normais, nas quais havia a inclusão desse componente curricular, conforme o artigo $9^{\circ}$ da lei educacional de 1879. Além disso, a aprovação em Filosofia era um requisito para a admissão em alguns cursos superiores, ainda conforme exigência do mesmo decreto. É importante salientar que tudo isso estava no papel, ainda que na prática, muito não tenha chegado à concretização. 
O ensino de Filosofia durante o período imperial permaneceu predominantemente propedêutico, com um tom livresco, enciclopédico, tanto a nível nacional, como local. Ainda que neste século, com a vinda da família real portuguesa para o Brasil, proporcionando a criação da imprensa, de bibliotecas e escolas superiores, o que para alguns seria um momento oportuno para a criação de uma faculdade nacional de filosofia (BROCANELLI, 2010), houve uma predileção pela faculdade de direto.

As idas e vindas deste saber no ensino secundário nos mostram que não há nada de tão novo nos ataques levantados contra a Filosofia no ensino médio - antigo secundário. Parece haver algum perigo nas esquinas do filosofar, o qual inquieta e nos leva à questão: que filosofia, a de ontem e a de hoje? O que ela tem de tão perigosa? Nos coloquemos a pensar.

\section{AS REFORMAS E O ENSINO DE FILOSOFIA (1889 - 1929)}

O período, marcado entre a década de 30 e 70 do século XIX, marca o apogev e o declínio de uma corrente filosófica chamada ecletismo, no Brasil, a qual defendia uma espécie de humanismo filosófico. Porém, nos anos 70 no mencionado século, surge um movimento de combate à essas ideias, chamado de Escola do Recife, o qual propunha ideias novas, a adoção de posições próprias, a defesa do espírito crítico, conforme aponta Brocanelli (2010).

O ano de 1889 trouxe consigo um momento de virada política, com a proclamação da República. A partir de então, em termos educacionais, uma série de reformas acompanharam as quatro primeiras décadas do novo regime. Foram pelo menos 05 entre 1890 e 1929. O que destacamos destas reformas foi o estabelecimento do Ginásio Nacional (Colégio Pedro II) como modelo e padrão para o ensino secundário, o que ocorreu com a primeira reforma educacional, promovida por Benjamin Constant.

O curso do Liceu de Alagoas, acompanhando a proposta da reforma de Constant, entrou em harmonia com o currículo do Ginásio Nacional, no ano de 1893. Lá, no Colégio Pedro II, permaneceu a cátedra de Filosofia, o que nos levar a supor que aqui no Liceu Alagoano havia a presença da Filosofia também. Certo é que em 1900, por meio do decreto 1. 741, de 06 de fevereiro, o ensino de História da Filosofia foi suprimido, criando-se a cadeira de Lógica (COSTA, 1931).

A presença do ensino de Filosofia em Alagoas, além do Liceu e das cadeiras espalhadas no interior do estado, ganhou nova expressividade, em 1902, com a instalação do Seminário Diocesano. "Contando já desde sua fundação com os cursos de Filosofia e Teologia [...] aquela instituição foi desde o início, objeto de cuidados especiais por recomendação do próprio Papa" (VERÇOSA, 1997, p. 24). Primeiro, foi instalado em Marechal Deodoro, depois, transferido para Maceió ao prédio próprio, no qual se encontra atualmente. Vale lembrar que aqui estamos falando daquela Filosofia eclesiástica exercida desde os tempos coloniais.

A reforma ocasionada em 1911, a qual estava a cargo de Rivadávia Correira, extinguiu a Filosofia do currículo do Colégio Pedro II, referência nacional para o ensino secundário, a qual só retornou ao currículo em 1915, com a nova reforma educacional aplicada por Carlos Maximiliano. No decreto da nova reforma, a Filosofia aparece como exigência do vestibular:

Art. 81. A prova oral do exame vestibular versará sobre elementos de Physica e Chimica e de Historia Natural, nas escolas de Medicina; sobre Mathematica Elementar, na Escola Polytechnica, e sobre Historia Universal, Elementos de Psychologia e de Logica e Historia da Philosophia por meio da exposição das doutrinas das principaes escolas philosophicas, nas Faculdades de Direito [grifo nosso] (BRASIL, 1915, p. n.). 
A volta da Filosofia do Direito ao currículo das Faculdades de Direito, a qual havia sido anteriormente suprimida, é um ponto a ser destacado no decreto de 1915, que tornava obrigatória a disciplina no primeiro ano. Com relação ao ensino secundário, a reforma de 1925, conhecida por Reforma Rocha Vaz, estabeleceu a criação da cadeira de Filosofia para o quinto ano do curso secundário; e a cadeira de História da Filosofia, para o sexto ano (BRASIL, 1925).

Os primeiros quarenta anos da República do Brasil preservaram o caráter elitista e difuso da educação. O curso secundário com seu caráter propedêutico, com ênfase nas áreas de Matemática e Ciências e menor apreço as chamadas Humanidades; o ensino superior, por sua vez, manteve as características do tempo do Império, com escolas isoladas e predominância do ensino profissionalizante; já as demais modalidades de ensino permaneceram na periferia das preocupações dos governos e das reformas.

\section{PRESENÇAS E AUSÊNCIAS DO ENSINO DE FILOSOFIA (1930 - 2017)}

A partir de 1930, a educação brasileira viveu um novo momento, pois o movimento dos chamados escolanovistas ganhava força e a sistematização do ensino, em todas as etapas, níveis e modalidades começava a ser algo possível de se alcançar. É deste período a criação do Ministério da Educação. Também é deste período a introdução, na Constituição de 1934, de um capítulo especial sobre educação, o qual a estabelecia como direito de todos (PILETTI; PILETTI, 1987).

A década de 1930 marcou ainda a chegada da "missão francesa" ao Brasil, com o objetivo de contribuir para a criação de um departamento de filosofia na USP, criada em 1934, num modelo de assimilação e imitação. Tais filósofos, vindos da França, por influência de Vitor Cousin, tinham a história da filosofia como centro, tornando o ensino praticado o que se chamou de filosofia eclética. Estudar um texto não seria nada mais que interpretá-lo (SILVA, 2016).

O ensino de Filosofia, nesse contexto, aparecia no segundo ciclo do ensino secundário, apenas para aqueles alunos que desejavam cursar a Faculdade de Direito. Por meio da reforma no ensino secundário, empreendida por Francisco Campos, este passava a ser dividido em dois ciclos, nos quais o primeiro se destinava a uma formação geral, enquanto o segundo, complementar, apresentava característica mais propedêutica, de preparação para o Ensino Superior.

A presença da Filosofia no Ensino Superior era fecunda, inclusive, na criação das primeiras faculdades das universidades, como a Faculdade de Filosofia, Ciências e Letras, junto à Universidade de São Paulo, em 1934; e a Faculdade Nacional de Filosofia, Ciências e Letras, em 1937, junto à Universidade do Rio de Janeiro. Essas faculdades, em geral, tinham três finalidades: preparar técnicos para exercer atividades administrativas na administração pública; preparar os candidatos ao magistério dos ensinos secundário e normal; e realizar pesquisas nos vários domínios da cultura.

A criação dessa faculdade em Alagoas, deu-se um tanto tardiamente, em comparação com outros estados. Foi em 1950, a partir de um complexo de escolas localizado no bairro do Farol, administrado pela Sociedade Guido de Fontgalland, que se fundou a Faculdade de Filosofia. Conforme nos atesta Verçosa (1997):

Pelas mãos do principal proprietário desse complexo, um padre católico, o empreendimento buscou, antes de mais nada, ainda no começo de 1950, a primeira inspiração e o modelo de organização nas duas instituições ligadas à Igreja Católica que existiam em Recife a Faculdade Católica de Filosofia e a Faculdade de Filosofia do Recife (VERÇOSA, 1997, p. 92 ). 
O objetivo dessa nova instituição, ainda segundo Verçosa (1997) era a de formar professores para o ensino secundário, o qual tinha sua oferta expandida cada vez mais, tanto na capital quanto no interior. Além disso, a formação dos técnicos para o Departamento Estadual de Educação sustentava a razão de existir da faculdade. Assim como acontecia nas faculdades congêneres, como dito acima, a Faculdade de Filosofia aqui fundada contava com outros cursos de formação de professores.

A influência da Igreja Católica, uma filosofia eclesiástica, parece ter relevância ainda nesse período, anos depois da presença pioneira dos jesuítas. A própria fundação da Faculdade de Filosofia se deu graças ao trabalho do padre Teófanes Augusto de Araújo Barros, natural do município alagoano de São José da Laje. Além desse grande empreendimento, se deve ao sacerdote católico a Campanha Nacional de Educadores Gratuitos, de 1943, a qual instituiu 54 unidades escolares ginasiais e colegiais na capital e no interior do estado, e ainda, a criação do Centro de Estudos Superiores de Maceió - CESMAC, um importante ambiente de ensino superior do estado até os dias de hoje.

A Faculdade de Filosofia foi o embrião do que na década seguinte se denominou Universidade de Alagoas. Juntamente com essa faculdade, a universidade recém-criada contava com os cursos de Medicina, Direito, Engenharia, Odontologia e Ciências Econômicas. Posteriormente, a instituição passou a se chamar Universidade Federal de Alagoas, a qual é a mais importante instituição de ensino superior do estado.

A reforma de Francisco Campo foi seguida pela reforma de Gustavo Capanema, o qual reformulou a organização do ensino secundário, que possuía 07 anos de duração, dividindo-se em Ginásio (04 anos) e Colegial (03 anos), este último dividido em clássico, com ênfase nas humanidades; e científico, com ênfase nas ciências (ARANHA, 2006). A Filosofia era ensinada na terceira série tanto do curso clássico quanto do curso científico. Assim determinava a lei sobre esse curso:

Art. $4^{\circ} \mathrm{O}$ curso clássico e o curso científico, cada qual com a duração de três anos, terão por objetivo consolidar a educação ministrada no curso ginasial e bem assim desenvolvê-la e aprofundá-la. No clássico, concorrerá para a formação intelectual, além de um maior conhecimento de filosofia, um acentuado estudo das letras antigas; no curso científico, essa formação será marcada por um estudo maior das ciências [grifo nosso] (BRASIL, 1942, p. n.).

O último registro que apresentamos da presença do ensino de Filosofia em Alagoas foi de 1900, no Liceu Alagoano. Através do exposto acima, podemos afirmar que pelo menos desde a década de 1940 esse ensino permanecia no ensino secundário das escolas alagoanas e assim permaneceu até os finais da década de 1960 ou até mais, se recordarmos o trabalho incansável do padre Teófanes em prol da educação alagoana.

A criação do Instituo Brasileiro de Filosofia, em 1949, e a publicação da Revista Brasileira de Filosofia, em 1951, constituem-se como marcas importantes para a criação do pensamento filosófico brasileiro (BROCANELLI, 2010), uma vez que até então, predominava a reprodução do pensamento estrangeiro - predominantemente europeu - ou uma mescla entre os dois tipos de pensamento. A realização de 03 Congressos Nacionais de Filosofia na década de 50 (1950, 1953 e 1959) também contribuíram para esse novo momento. Essa nova configuração possibilitou falar em uma maioridade filosófica brasileira.

A década de 1960, num contexto macro, foi marcada pela criação da primeira Lei de Diretrizes e Bases da Educação, em 1961. Foram treze anos de intensos debates até que a lei fosse aprovada. O ensino secundário permaneceu organizado da mesma forma. A novidade foi para a composição curricular, a qual teria duas partes obrigatórias, uma determinada pelo Conselho 
Federal de Educação; a outra, pelos Conselhos Estaduais; e uma última de caráter optativo à escolha dos estabelecimentos de ensino (PILETTI; PILETTI, 1987).

O ensino de Filosofia, dentro desse contexto, apresentava caráter bastante enciclopédico, com desinteresse dos alunos e falta de participação ativa destes. Em 1957, o país contava com cinquenta faculdades de Filosofia, com um número de 1.010 alunos matriculados. Nos demais cursos superiores, a presença da Filosofia nos currículos é percebida nos cursos de Pedagogia, Ciências Sociais e até mesmo no curso de Física. No ensino secundário a situação não era tão diferente, quanto aos primeiros aspectos citados. Além disso, a presença do caráter propedêutico do ensino de Filosofia tornava a disciplina mais uma, não alcançando seu objetivo de formação moral e intelectual do adolescente (MORAES FILHO, 1956).

A não obrigatoriedade da Filosofia no ensino secundário, em 1961, a sua progressiva substituição, em 1969, com a criação das disciplinas de Educação Moral e Cívica e OSPB, as quais possuíam um conteúdo mais "adequado" ao contexto político da época, isto é, um caráter disciplinar e doutrinador, bem como a retirada definitiva, em 1971, contribuíram para uma intensa mobilização pela luta da obrigatoriedade e pela revalorização das humanidades no ensino secundário (COSTA, 2014).

As críticas ao ensino de Filosofia da época são as mais diversas, as quais nos levam a questionar se muitas dessas críticas não cabem a este ensino hoje. O caráter mercantilista deste ensino, com a abertura impensada de cursos de Filosofia, assumindo um caráter utilitário e profissional imediato (MORAES FILHO, 1956) nos leva a indagar se o mesmo não ocorre com o ensino de Filosofia hoje, ainda que, no momento atual, a Filosofia juntamente com a Sociologia estejam sob constantes ataques por parte de alguns setores da sociedade.

A década de 1970, pós golpe civil-militar, reservou para o ensino de Filosofia dias difíceis, "as matérias filosóficas, importantes para a reflexão e discussão, tornaram-se optativas para maior parte dos estudantes" (PILETTI; PILETTI, 1987, p. 238). Além disso, a determinação anterior que centrava a universidade em torno da Faculdade de Filosofia, Ciências e Letras foi extinta. No ensino secundário, perdeu seu espaço, juntamente com Sociologia e Psicologia.

A luta em defesa da Filosofia e do seu ensino levaram a criação da Sociedade de Estudos e Atividades Filosóficas, SEAF, uma entidade de nível nacional que propunha uma filosofia crítica e engajada, promovendo diversos debates, mesas redondas e seminários nessa intenção (COSTA, 2010). Em 1983, a fundação da Associação Nacional de Pós-Graduação em Filosofia (ANPOF), marcou um importante passo na defesa da Filosofia. Vale salientar que um ano antes, em 1982, a disciplina voltou a ser optativa, tornando-se alvo de diversas críticas da mídia da época, por isso.

Os anos seguintes permanecem como tempos difíceis para essas duas disciplinas. Após o fim da ditadura civil-militar, muitos anos ainda foram necessários para que essas disciplinas voltassem a figurar, pelo menos nominalmente, nos documentos oficiais sobre educação. Em 1996, foi aprovada a lei 9.394, Lei de Diretrizes e Bases da Educação (LDB), a qual propunha a Filosofia e Sociologia como conhecimentos necessários ao exercício da cidadania. Vale ressaltar que o projeto original da LDB, aprovado pela Câmara em 1993, incluía essas disciplinas como obrigatórias nos currículos do antigo ensino secundário, entretanto, por questões políticas, outro projeto foi aprovado no lugar do original.

A disputa pelo território dos currículos continuou. Em 1997, um projeto de lei foi apresentado pelo deputado (padre) Roque Zimmermann, o qual pretendia tornar a Filosofia e a Sociologia como disciplinas obrigatórias no ensino médio. Em 2001 o projeto foi aprovado, entretanto, o presidente da República da época acabou por vetar o projeto, alegando falta de pessoal capacitado para assumir este ensino e falta de recursos econômicos para contratação dos recursos humanos.

A não-obrigatoriedade legal não impedia que a Filosofia estivesse presente nos currículos do ensino médio. Muitos estados da federação, por iniciativa própria, haviam introduzido a disciplina em suas redes. Em Alagoas, por exemplo, a presença do ensino de Filosofia já era notada desde 
2004 (FAVERO, 2004). Até mesmo as escolas particulares haviam tomado essa medida, inclusive, no ensino fundamental, etapa em que a Filosofia se fazia presente em quase todos os estados.

A obrigatoriedade veio em 2008, com a aprovação da lei 11.683, a qual alterou o artigo 36 - IV da LDB/96, tornando obrigatório o ensino de Filosofia e Sociologia. A lei concedeu um prazo de quatro anos para que todas as séries do ensino médio fossem contempladas com a presença dessas disciplinas. $O$ fato representou um importante momento para o ensino dessas disciplinas, as quais gozaram de quase dez anos de estabilidade nos currículos.

O ano de 2017 trouxe uma nova reviravolta para a situação dessas disciplinas no currículo. A lei 13.415, do ano supracitado, conhecida como "reforma do ensino médio" retirou o IV do artigo 36 da LDB/96, e colocou a Filosofia, juntamente com a Educação Física, a Arte e a Sociologia como estudos e práticas, cabendo à Base Nacional Comum Curricular estabelecer como isso se dará na prática. Conforme nos alerta Obiols (2002, p. 36), "a filosofia na escola secundária sente-se ameaçada: cada reforma nos currículos pode deixá-la de fora, ante às pressões e exigências de uma educação que privilegie a capacitação técnico-científica dos alunos".

\section{CONCLUSÃO}

A história do ensino de Filosofia é marcada por um movimento pendular de constantes idas e vindas do currículo da educação formal. O início dessa prática em terras brasileiras traz consigo a característica de uma filosofia eclesiástica, subserviente. No decorrer do tempo, assume um modo enciclopédico, mais ligado a decorar nomes, datas e ideias, do que se pôr em movimento no exercício do pensar.

A história de idas e vindas nos apontam o quão ameaçador pode ser o ensino de Filosofia, quando consegue levar àquele retorno do pensamento sobre si mesmo e fazer pensar o que antes não se pensava ou o saber o que antes não se sabia, quando consegue nos fazer enxergar além do que os olhos podem ver.

O mundo cada vez mais submetido à lógica do capital e do mercado, cada vez mais utilitarista e pragmático, no qual as coisas obtêm seu valor de acordo com a utilidade imediata com que se apresentam. Nesse mundo, a Filosofia parece não ter muita importância e serventia. Deveria ela submeter-se a essa lógica? Deveria ela esvaziar-se para se dar de qualquer maneira? É possível pensar uma Filosofia que não seja subserviente?

A afirmação de que a Filosofia está em constante perigo, porque é potencialmente perigosa, encontra seu fundamento na realidade observada, nas atitudes tirânicas, as quais, quase sempre, se voltam para subjugar áreas de conhecimento como a Filosofia. É cada vez mais urgente que a Filosofia, que o seu ensino se reafirme por aquilo que ela possui de específico, por aquilo que somente ela pode oferecer aos jovens de nossos dias. Cumpre-nos colocar na busca constante de sua especificidade para que possamos construir uma nova história dessa prática, com mais permanências e continuidades.

\section{REFERÊNCIAS}

ARANHA, Maria Lúcia de Arruda. História da Educação e da Pedagogia. 3ed. São Paulo: Moderna, 2006.

BRASIL. "Lei de 15 de outubro de 1827". Disponível em: http://www2.camara.leg.br/legin/fed/ lei_sn/1824-1899/lei-38398-15-outubro-1827-566692-publicacaooriginal-90222-pl.html Acesso em: 21 jun. 2017. 
BRASIL. "Decreto no 11.530 de 18 de março de 1915". Disponível em: http://www2.camara.leg. br/legin/fed/decret/1910-1919/decreto-1 1530-18-marco-1915-522019-republicacao-97760-pe.html Acesso em: 07 ago. 2017.

BRASIL. "Decreto n 16. 782-A de 13 de janeiro de 1925". Disponível em: https://www.planalto.gov. br/ccivil_03/decreto/1910-1929/d16782a.htm Acesso em: 07 ago. 2017.

BRASIL. "Lei n 4.024 de 20 de dezembro de 1961". Disponível em: https://www2.camara.leg.br/ legin/fed/lei/1960-1969/lei-4024-20-dezembro-1961-353722-publicacaooriginal-1-pl.html. Acesso em: 23 jun. 2017.

BRASIL. "Lei n 9. 394 de 20 de dezembro de 1996". In: CÂMARA DOS DEPUTADOS. Legislação brasileira sobre educação". 4ed. Brasília: Câmara dos Deputados, Edições Câmara, 2017.

BRASIL. "Lei n 11.684 de 02 de junho de 2008". Disponível em: http://www.planalto.gov.br/ccivil_03/_Ato2007-2010/2008/Lei/L1 1684.htm. Acesso em: 23 jun. 2017.

BRASIL. "Lei n 13.415 de 16 de fevereiro de 2017". Disponível em: http://www.planalto.gov.br/ccivil_03/_Ato2015-2018/2017/Lei/L13415.htm. Acesso em: 23 jun. 2017.

BROCANELLI, Cláudio Roberto. O ensino de Filosofia e o filosofar e a possibilidade de uma experiência filosófica na atualidade. Tese (Doutorado em Educação). Faculdade de Filosofia e Ciências/ Unesp, Marília, 2010.

CAETANO, Antônio Filipe Pereira. "Existe uma Alagoas Colonial? Notas preliminares sobre os conceitos de uma conquista ultramarina". Revista Crítica Histórica, n. 01, p. 12 - 34, jun., 2010.

COSTA, Craveiro. Instituições Públicas e Instituições Culturais de Alagoas. Maceió: Imprensa Oficial de Alagoas, 1931.

COSTA, Regis Clemente da. O ensino de Filosofia no estado do Paraná: dilemas e contradições entre ensinar filosofia e ensinar a filosofar na perspectiva da formação humana. Dissertação (Mestrado em Educação). Universidade Estadual de Ponta Grossa, Ponta Grossa, 2014.

DOMINGUES, Ivan. Filosofia no Brasil: legados e perspectivas - ensaios metafísicos. São Paulo:Unesp Digital, 2017.

FAVERO, A. A.; CEPAS, Felipe; GONTIJO, P. E.; GALLO, Silvio; KOHAN, W. "O ensino de Filosofia no Brasil: um mapa das condições atuais". Caderno Cedes, Campinas, vol. 24, n. 64, p. 257 - 284, set./ dez., 2004.

MORAES FILHO, Evaristo de. O Ensino da Filosofia no Brasil. Rio de Janeiro: Biblioteca Nacional, 1959.

OBIOLS, Guillermo. Uma introdução ao ensino da filosofia. ljuí: Unijuí, 2002.

PILETTI, Claudino; PILETTI, Nelson. Filosofia e História da Educação. São Paulo: Ática, 1987.

SANTOS, Ivanildo Gomes dos. As raízes do ensino secundário público na província das Alagoas: o Liceu Alagoano (1849 - 1889). Disponível em: http://sbhe.org.br/novo/congressos/cbhe7/ pdf/07-\%20HISTORIA\%20DAS\%2OINSTITUICOES\%20E\%2OPRATICAS\%20EDUCATIVAS/AS\%20RAIZES\%20 DO\%20ENSINO\%2OSECUNDARIO\%2OPUBLICO\%20NA\%20PROVINCIA\%20DAS\%20ALAGOAS\%20-\%20 O\%20LICEU\%20ALAGOANO\%20(1849-1889).pdf Acesso em: 04 ago. 2017. 
SILVA, Éliton Dias da. Não se ensina filosofia, se ensina a filosofar: a controversa presença da história da filosofia na formação docente. Tese (Doutorado em Educação). Faculdade de Filosofia e Ciências/Unesp, Marília, 2016.

VERÇOSA, Élcio de Gusmão. História do Ensino Superior em Alagoas: verso e reverso. Maceió: EDUFAL, 1997.

VERÇOSA, Élcio de Gusmão. Cultura e Educação nas Alagoas: histórias, histórias. 4ed. Maceió: EDUFAL, 2006. 